\title{
WORKSHOP PARENTING TINGKAT KECAMATAN MAUPONGGO
}

\author{
Efrida Ita $^{1)}$ dan Elisabeth Tantiana Ngura ${ }^{2)}$ \\ Program Studi Pendidikan Guru Pendidikan Anak Usia Dini \\ Sekolah Tinggi Keguruan dan IImu Pendidikan Citra Bakti \\ 1)evoletelvo@gmail.com, ${ }^{2)}$ elisabethngura@gmail.com
}

\section{Histori artikel}

Received:

15 Maret 2020

Accepted:

12 April 2020

Published:

15 April 2020

\begin{abstract}
Abstrak
Tujuan dari kegiatan pengabdian kepada masyarakat ini adalah 1) membekali kompetensi orang tua dalam memahami stimulasi sejak bayi dalam kandungan, 2) membekali kompetensi orang tua dalam memahami cara pola asuh yang tepat untuk diberikan kepada anak. Hal tersebut penting diperhatikan berkaitan dengan penanganan Pendidikan Anak Usia Dini di lembaga (center base) tidak dapat dilepaskan dari penanganan PAUD di rumah (home base), keduanya saling terkait dan sejalan. Pembelajaran anak di lembaga yang hanya dapat mengisi anak sebesar $20 \%$ dimanfaatkan sebaik-baiknya oleh guru. Namun tidak menjadi berarti apabila saat anak berada dalam lingkungan keluarga tidak mendapat pendidikan yang tepat seperti yang dilaksanakan pada lembaga. Metode yang digunakan dalam pelaksanaan kegiatan pengabdian ini adalah berbentuk pelatihan dalam pemberian stimulasi dan pola asuh bagi orang tua terhadap anak. Karena hal ini penting bagi keluarga dalam hal ini orang tua untuk menyesuaikan pembelajaran bagi anak di lembaga PAUD dan di rumah sehingga apa yang anak belajar di lembaga dalam hal ini sekolah akan sama dengan yang anak dapatkan atau belajar di rumah. Hasil yang diperoleh dari pelaksanaan pengadian kepada masyarakat ini adalah para orang tua dibekali dengan kompetensi dalam memahami stimulasi sejak bayi dalam kandungan dan dilatih simulasi stimulasi edukatif bagi anak sehingga memahami cara pola asuh yang tepat untuk diberikan kepada anak guna mengoptimalkan tumbuh kembang anak sejak dari dalam kandungan.
\end{abstract}

Kata-kata Kunci: pola asuh orangtua, stimulasi anak 
Abstract. The purposes of this public service activity are: 1) to provide the parental competence in understanding stimulation since the baby is in the womb, 2) to provide the parental competence in understanding appropriate parenting ways to be given to children. It is important to note that related to the handling early childhood education in an institution (center base) cannot be separated from the handling of early childhood education at home (home base). Both of them complement each other and must be in harmony. The children's learning in institutions that can only fill children by $20 \%$ is used as well as possible by the teacher. But it does not mean that when the child is in the family environment does not get the right education as implemented at the institution. The method used in the implementation of this public service activity is in the form of training in providing stimulation and parenting to the parents of children. For this reason, it is important for the family in this case parents to adjust learning for children in early childhood education institutions and at home so that what children learn in the institution in this case the school will be the same as what children get or learn at home. The results obtained from the implementation of the public service are the parents are provided with the competence in understanding stimulation since the baby is in the womb and trained in educational stimulation simulations for children so that they understand the proper parenting methods to be given to children to optimize children's growth and development from the womb.

Keywords: workshop parenting, child stimulation

\section{PENDAHULUAN}

Penanganan Pendidikan Anak Usia Dini di lembaga (center base) tidak dapat dilepaskan dari penanganan PAUD di rumah (home base), keduanya saling terkait dan sejalan. Pembelajaran anak di lembaga yang hanya dapat mengisi anak sebesar $20 \%$ dimanfaatkan sebaik-baiknya oleh guru. Namun tidak menjadi berarti apabila saat anak berada dalam lingkungan keluarga tidak mendapat pendidikan yang tepat seperti yang dilaksanakan pada lembaga. Fakta yang terjadi di Kecamatan Mauponggo adalah rendahnya kesadaran dan pengetahuan orang tua mengenai pola asuh anak; Masih ditemui orang tua yang memiliki anak yang terlambat berbicara, akan tetapi dibiarkan saja, dengan tidak diberikan stimulasi yang benar agar anak dapat dengan cepat dapat berbicara. Begitu juga orang tua yang memiliki anak yang sudah berusia 2 tahun, tetapi belum dapat berjalan. Bukannya memberikan stimulasi, para orang tua cenderung membawa anak-anak mereka ke dukun untuk berobat. Padahal seharusnya masalah anak tersebut dikomunikasikan atau dikonsultasikan dengan pihak puskesmas atau ke dokter untuk diketahui penyebabnya, dan agar bisa segera diatasi. Salah satu cara yang cukup efektif adalah dengan memberikan stimulasi edukatif untuk perkembangan anak. Terkait pola asuh orang tua ditemukan beberapa kasus seperti orang tua yang terlalu memanjakan anaknya (anak usia 2-6 tahun), bahkan memberikan kebebasan kepada anaknya untuk selalu bermain gadget. Padahal hal tersebut tidak bagus untuk pertumbuhan dan perkembangan anak.

Bertolak dari masalah-masalah yang ditemukan di atas, maka penting bagi keluarga dalam hal ini orang tua untuk menyesuaikan pembelajaran bagi anak di lembaga PAUD dan di rumah sehingga apa yang anak belajar di lembaga dalam hal ini sekolah akan sama dengan yang anak dapatkan atau belajar di rumah. Hal ini akan menjadi pembiasaan bagi anak. Ketika anak berada di rumah dan lingkungan, persentasi terbesarnya mencapai 80 persen, sedangkan ketika anak berada di sekolah/lembaga pendidikan persentasinya hanya 
20\% (Latif, dkk, 2013: 261). Ini berarti, anak pada dasarnya lebih banyak menghabiskan waktu bersama keluarga daripada di sekolah. Apabila keluarga dan juga lingkungan tidak mampu mendukung proses pembelajaran yang tepat bagi anak, yaitu melalui kegiatan bermain, maka dengan sendirinya anak akan kehilangan sebagian proses perkembangannya.

Setiap orang tua wajib memberikan perlindungan, kasih sayang, dan lingkungan belajar yang kondusif di rumah untuk mendukung proses pendidikan anak. Sebagai orangtua, sebaiknya mampu melihat beberapa kelebihan pada anaknya, baik yang tampak secara kasat mata maupun berupa bakat terpendam. Orang tua hendaknya lebih memfokuskan perhatian pada kelebihan yang dimiliki anak dan mengarahkannya ke arah yang tepat. Menurut Lidyasari (2012: 2), model perilaku orang tua secara langsung maupun tidak langsung akan dipelajari dan ditiru oleh anak. Orang tua merupakan lingkungan terdekat yang selalu mengitarinya juga menjadi idola anak. Apabila anak menyaksikan kebiasaan baik dari orang tuanya, maka anak akan dengan cepat menirunya, demikian sebaliknya apabila orang tua berperilaku buruk, maka anak akan meniru perilakunya. Anak akan meniru bagaimana orang tua akan bersikap, berbicara, mengekspresikan harapan, tuntutan, dan kritikan satu dengan yang lain, menanggapi serta memecahkan masalah, dan mengungkapkan perasaan dan emosinya. Pemberian stimulasi dan pola asuh ini yang disebut dengan parenting.

Parenting merupakan keterampilan orang tua dalam mengasuh anak. Pada masa ini orang tua bisa memberikan pola pengasuhan efektif dan bersifat membangun untuk anak. Karena dari pola asuh yang efektif dan berkualitas tersebut, dapat membangun potensi yang ada dalam pribadi anak, sehingga anak dapat menjadi pribadi yang baik, memiliki prestasi tinggi serta dapat memecahkan masalah dan mengendalikan emosinya dengan baik (Ismaniar \& Sunarti, 2018)

Berdasarkan paparan kenyataan di atas, maka dilakukan kegiatan pengabdian pada masyarakat dengan judul, "Workshop Parenting Tingkat Kecamatan Mauponggo." Berdasarkan hasil diskusi bersama Ketua Penggerak Bidan Tingkat Kecamatan Mauponggo teridentifikasi masalah dalam pemberian stimulasi dan teknik pola asuh orang tua, yaitu banyak orang tua dewasa ini belum sepenuhnya memahami bagaimana pemberian stimulasi sejak bayi dalam kandungan dan penerapan pola asuh yang baik.

\section{METODE PELAKSANAAN}

Setelah dilakukan analisis terhadap akar penyebab suatu masalah seperti yang telah diuraikan di atas, maka metode yang digunakan dalam melaksanakan kegiatan pengabdian ini adalah berbentuk pelatihan kepada orang tua dalam pemberian stimulasi dan pola asuh terhadap anak. Sasaran atau subyek untuk dilibatkan dalam program pengabdian ini adalah 
para bidan se-kecamatan Mauponggo dan para Ibu hamil yang berjumlah 20 orang. Adapun rincian kegiatan yang dilakukan antara lain: memberikan materi tentang stimulasi dan parenting, 2) pelatihan cara menstimulasi bayi dalam kandungan bersama para bidan dan ibu hamil dan sharing mengenai pola asuh yang selama ini diterapkan oleh orang tua.

\section{HASIL DAN PEMBAHASAN}

Hasil

Untuk mengawali kegiatan workshop parenting dilakukan sosialisasi program P2M terkait dengan pengabdian bagi dosen dibidang IImu Pengetahuan dan Teknologi (IPTEK). Pemateri menyampaikan pentingnya stimulasi sejak bayi dalam kandungan dan jenis-jenis pola pengasuhan yang dapat diterapkan untuk anak usia dini. Rangkaian workshop parenting yaitu: 1) memberikan materi tentang stimulasi sejak dini bagi anak, 2) pelatihan cara menstimulasi anak dengan baik dan benar sesuai usia perkembangan anak. Hasil yang diperoleh dari pelaksanaan pengadian kepada masyarakat ini adalah para orang tua dibekali dengan kompetensi dan pelatihan dalam memahami stimulasi sejak bayi dalam kandungan, dan memahami cara pola asuh yang tepat untuk diberikan kepada anak.

Berikut dipaparkan dokumentasi saat kegiatan workshop parenting.

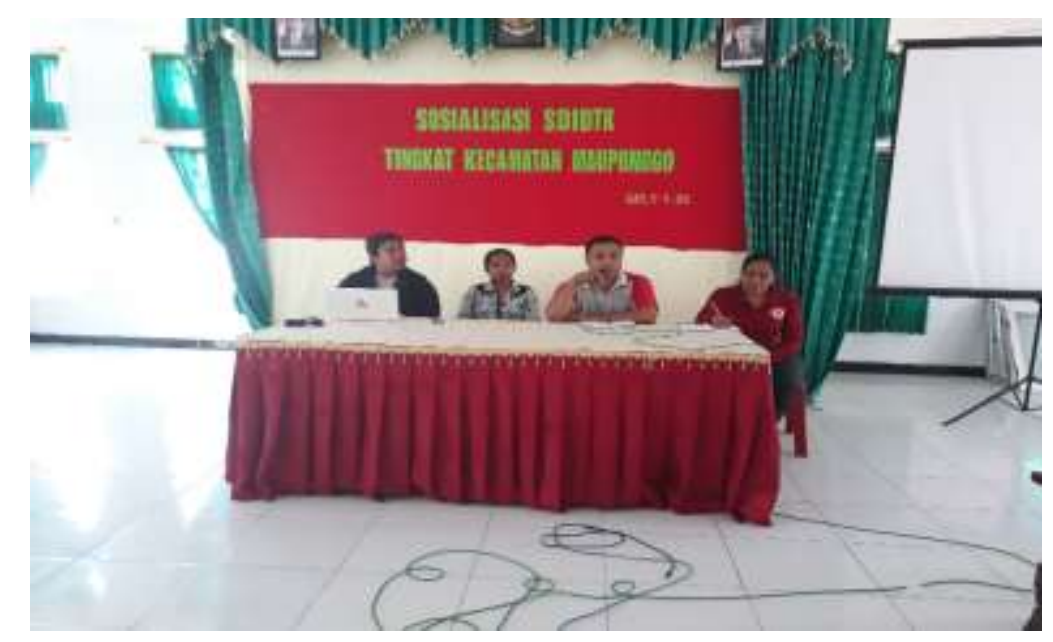

Gambar 1. Kepala Puskesmas Mauponggo Memberikan Arahan Umum Terkait Kegiatan 


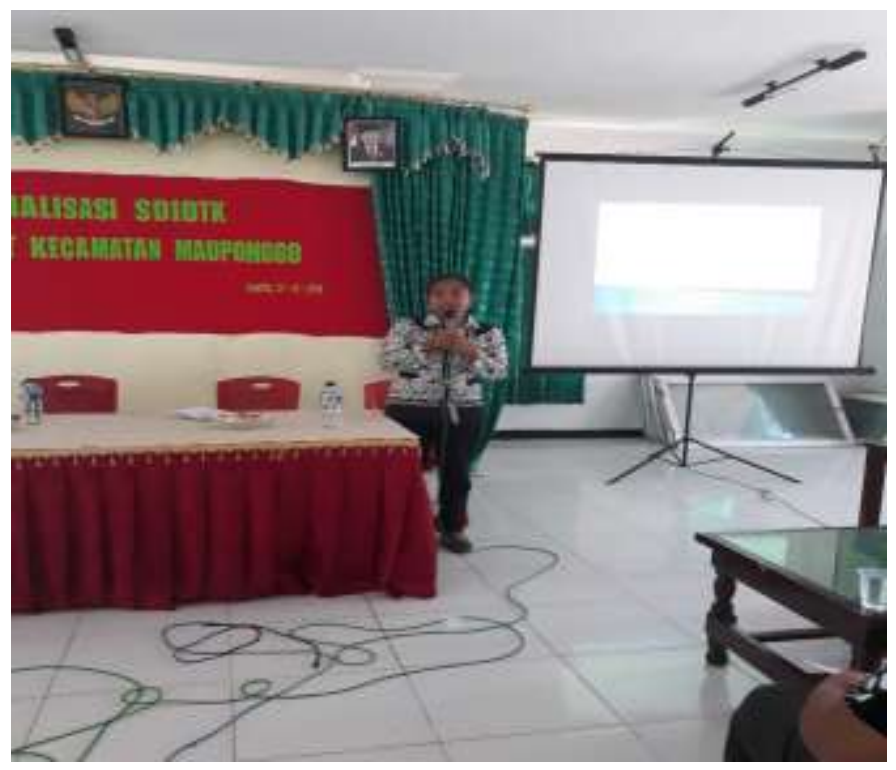

Gambar 2. Penyampaian Materi tentang Stimulasi Intervensi Dini

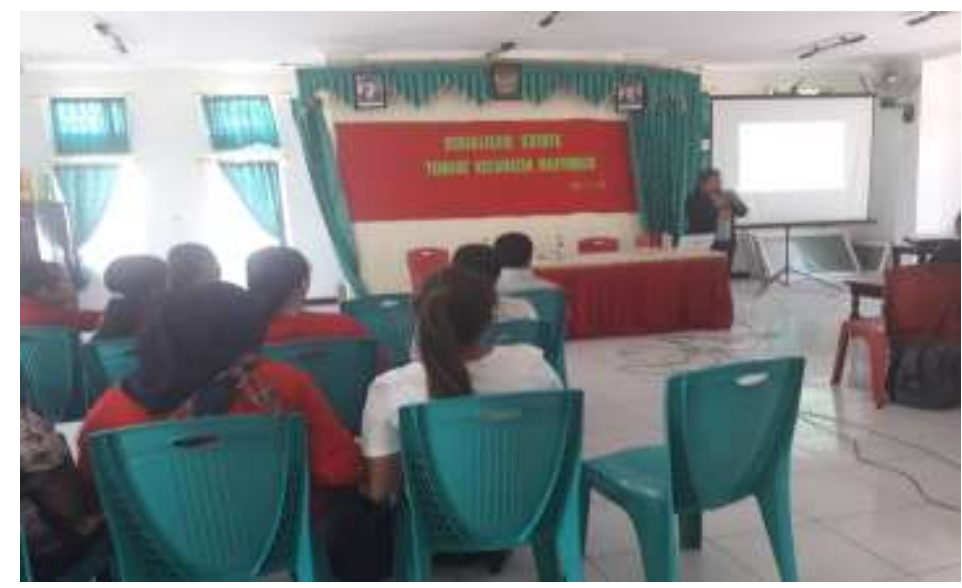

Gambar 3. Penyampaian Materi tentang Parenting

\section{Pembahasan}

Workshop parenting dilaksanakan di ruang pertemuan Puskesmas Mauponggo pada tanggal 17 November 2018. Peserta pelatihan terdiri dari para bidan dan para ibu hamil berjumlah 20 orang. Para peserta dibekali langkah-langkah pemberian stimulasi untuk tingkat usia anak yang berbeda dan diberikan contoh pola asuh yang baik sesuai karakteristik anak.

Kegiatan pertama adalah membekali kompetensi orang tua dalam menstimulasi sejak bayi dalam kandungan. Pada sesi ini, pemateri pertama yakni Efrida ita, S.S, M.Pd menjelaskan tentang konsep stimulasi, dan pentingya pemberian stimulasi bagi bayi sejak dalam kandungan serta dilakukan simulasi pada beberapa ibu hamil yang hadir. Tidak hanya itu, pemberian gizi yang seimbang juga dapat mendukung tumbuh kembang anak, dan hal ini bukan saja menjadi tugas para bidan, tetapi lebih kepada tanggung jawab orang tua. Untuk 
kegiatan stimulasi ini sejalan dengan beberapa teori stimulus-respon (psikolinguistik) yang dikemukakan oleh para ahli, diantaranya: 1) teori pembiasaan klasik dari Pavlov, stimulus dilakukan berulang-ulang dan dibiasakan sehingga menimbulkan respon, 2) teori penghubung Thorndike, untuk memperoleh hasil yang baik, maka diperlukan latihan yang berulang dan teratur, 3) teori behaviorsme dari Watson, dalam proses pembelajaran sebagian perilaku yang terjadi adalah akibat pengaruh lingkungan.

Kegiatan kedua adalah membekali kompetensi orang tua dalam memahami cara pola asuh (parenting) yang tepat untuk diberikan pada anak. Sesi kedua ini, pemateri kedua yakni Elisabeth Tantiana Ngura, M.Pd, menjelaskan konsep pola asuh, dan berbagai jenis pola asuh yang dapat diterapkan orang tua terhadap anak. Dalam beberapa diskusi ada beberapa orang tua mensharing mengenai pola asuh atau cara mereka mengasuh anakanak mereka selama ini. Hal yang membuat mereka bingung adalah pola asuh jenis apa yang selama ini sudah mereka terapkan. Inilah juga yang menjadi alasan yang mendasar dilakukannya workshop ini. Pemahaman orang tua mengenai parenting (pola asuh), memang perlu dibekali, tujuannya agar orang tua mengetahui bahwa setiap anak perlu diterapkan pola asuh yang berbeda, ini disesuaikan dengan karakteristik anak.

Dalam memberikan pelatihan, para pemateri menggunakan dan memanfaatkan para ibu hamil dan para bidan, dengan begitu sangat memudahkan dalam pelaksanaan simulasi. Para peserta juga diberikan kesempatan untuk sharing tentang pengalaman mereka menjadi orang tua sehingga situasi kegiatan menjadi dinamis.

\section{KESIMPULAN}

Program pendidikan anak usia dini pada dasarnya bersifat holistik dan terintegrasi. Keterlibatan penuh orang tua dalam mendidik anak dinilai bukan saja dapat meningkatkan minat tetapi juga motivasi anak untuk belajar. Fakta menyebutkan bahwa masih ada orang tua yang belum memahami cara mendidik anak. Oleh karena itu, kegiatan parenting atau pemberdayaan orang tua dalam mendidik anak dalam keluarga perlu diadakan.

Kegiatan pengabdian ini menjadi waktu yang tepat untuk saling berbagi dan mengedukasi para orang tua dan para bidan dalam pemberian stimulasi serta penerapkan pola asuh yang tepat terhadap anak sehingga melahirkan dan membentuk anak yang berkarakter kuat. Dengan kata lain, ketidaktahuan orang tua dalam memberi stimulasi kepada anak dapat berdampak kurang baik pada pertumbuhan dan perkembangan anak. Kesimpulan yang dapat diambil dari kegiatan pengabdian kepada masyarakat ini adalah 1) orang tua dibekali kompetensi dalam memahami stimulasi sejak bayi dalam kandungan, 2) orang tua dibekali kompetensi dalam memahami cara pola asuh yang tepat untuk diberikan kepada anak. 


\section{DAFTAR PUSTAKA}

Latif, Mukthar, Zukhairina, Zubaidah, R., \& Afandi, M. (2013). Orientasi baru pendidikan anak usia ini: teori dan aplikasi. Jakarta: Kencana.

Lidyasari, A.T (2013). Pola asuh otoritatif sebagai saran pembentukan karakter anak dalam seting keluarga. Jurnal Yogyakarta: PGSD FIP UNY.

Ismaniar dan Vevi S. (2018). Buku ajar pelatihan parenting. Jurusan Pendidikan luar Sekolah FIP UNP: Padang. 